\title{
Solar-Blind AlGaN-Based p-i-n Photodiodes With Low Dark Current and High Detectivity
}

\author{
N. Biyikli, I. Kimukin, O. Aytur, and E. Ozbay
}

\begin{abstract}
We report solar-blind $\mathrm{Al}_{x} \mathrm{Ga}_{1-x} \mathrm{~N}$-based heterojunction p-i-n photodiodes with low dark current and high detectivity. After the p+ GaN cap layer was recess etched, measured dark current was below $3 \mathrm{fA}$ for reverse bias values up to $6 \mathrm{~V}$. The device responsivity increased with reverse bias and reached $0.11 \mathrm{~A} / \mathrm{W}$ at $261 \mathrm{~nm}$ under 10-V reverse bias. The detectors exhibited a cutoff around $283 \mathrm{~nm}$, and a visible rejection of four orders of magnitude at zero bias. Low dark current values led to a high differential resistance of $9.52 \times 10^{15} \Omega$. The thermally limited detectivity of the devices was calculated as $4.9 \times 10^{14} \mathrm{~cm} \cdot \mathrm{Hz}^{1 / 2} \mathrm{~W}^{-1}$.
\end{abstract}

Index Terms-AlGaN, dark current, detectivity, heterostructure, high-performance, p-i-n photodiode.

$\mathbf{S}$ OLAR-BLIND detectors with long-wavelength cutoff around $280 \mathrm{~nm}$ have important applications including missile plume sensing, flame detection, chemical-biological agent sensing, and covert space-to-space communications [1]. With the advent in material growth of high-quality $\mathrm{Al}_{x} \mathrm{Ga}_{1-x} \mathrm{~N}$ ternary alloys, AlGaN-based solar-blind photodetectors emerged as a potential alternative for the photomultiplier tube (PMT) and silicon-based solar-blind detector technology. They have the advantage of intrinsic solar-blindness, and therefore, do not need complex and costly filters. In addition, AlGaN-based solar-blind detectors can operate under harsh conditions due to their wide bandgap and robust material properties [2]. Several research groups have demonstrated high-performance solar-blind photodetectors using $\mathrm{Al}_{x} \mathrm{Ga}_{1-x} \mathrm{~N}$ material system [3]-[12].

Detectivity is an important detector performance parameter which gives the signal-to-noise performance of the device. For low noise detection, detectivity should be as high as possible. The typical detectivity of a cooled PMT is about $D^{*}=4 \times$ $10^{14} \mathrm{~cm} \cdot \mathrm{Hz}^{1 / 2} \mathrm{~W}^{-1}$ around $300 \mathrm{~nm}$ [13]. A comparable detectivity performance $\left(D^{*} \sim 3 \times 10^{14} \mathrm{~cm} \cdot \mathrm{Hz}^{1 / 2} \mathrm{~W}^{-1}\right.$ at $275 \mathrm{~nm}$ ) was reported recently with a solar-blind AlGaN-based back-illuminated p-i-n photodiode [14]. In this letter, we report the design, fabrication, and characterization of solar-blind AlGaN p-i-n photodiodes with record dark current and detectivity performance. The measured dark current was below $3 \mathrm{fA}$ at $6-\mathrm{V}$ re-

Manuscript received March 4, 2004; revised April 5, 2004. This work was supported by NATO under Grant SfP971970, by the Turkish Department of Defense under Grant KOBRA-002, and by FUSAM-03.

N. Biyikli is with the Department of Electrical and Electronics Engineering, Bilkent University, Bilkent Ankara 06800, Turkey (e-mail: biyikli@ee.bilkent.edu.tr).

I. Kimukin and E. Ozbay are with the Department of Physics, Bilkent University, Bilkent Ankara 06800, Turkey.

O. Aytur is with the Department of Electrical and Electronics Engineering,

Bilkent University, Bilkent Ankara 06800, Turkey.

Digital Object Identifier 10.1109/LPT.2004.829526 verse bias and a PMT-exceeding solar-blind detectivity of $D^{*}=$ $4.9 \times 10^{14} \mathrm{~cm} \cdot \mathrm{Hz}^{1 / 2} \mathrm{~W}^{-1}$ at $267 \mathrm{~nm}$ was achieved.

The $\mathrm{p}$-i-n photodiode wafer was grown by metal-organic chemical vapor deposition on sapphire substrate. The detector structure was designed for front (p-side) illumination. The active absorption region of the photodiode was formed with a 100-nm-thick unintentionally doped $\mathrm{Al}_{0.45} \mathrm{Ga}_{0.55} \mathrm{~N}$ layer which was sandwiched between a 250-nm-thick $\mathrm{n}+\mathrm{GaN}$ layer and a 10-nm-thick p-type-doped $\mathrm{Al}_{0.45} \mathrm{Ga}_{0.55} \mathrm{~N}$ layer. To improve the p-ohmic contact quality, a 30-nm-thick p-type GaN cap layer was grown on top of $\mathrm{p}-\mathrm{Al}_{0.45} \mathrm{Ga}_{0.55} \mathrm{~N}$ layer. A five-step microwave compatible semiconductor fabrication process was utilized to complete the device fabrication [15]. In the first two steps, ohmic contacts were formed. A 250-nm deep dry-etch for $\mathrm{n}+$ ohmic contact was done via $\mathrm{CCl}_{2} \mathrm{~F}_{2}$-based reactive ion etching (RIE). This was followed by a Ti-Al (100/1000 $\mathrm{A})$ metallization. Then, Ni-Au (100/200 ̊) was deposited for p-type contact. Both contact metals were annealed at $700{ }^{\circ} \mathrm{C}$ for $1 \mathrm{~min}$. After the device mesas were defined and electrically isolated with RIE, the sample surface was passivated with a $\sim 200$-nm-thick $\mathrm{Si}_{3} \mathrm{~N}_{4}$ layer deposited using plasma-enhanced chemical vapor deposition at $350{ }^{\circ} \mathrm{C}$. The fabrication process ended with the formation of $\sim 0.6-\mu \mathrm{m}$-thick Ti-Au interconnect metal pads.

For device characterization, current-voltage $(I-V)$ and spectral responsivity measurements were carried out. To analyze the effect of p-type GaN cap layer on the dark current and responsivity performance, the measurements were done in two steps: before and after the recess etch of top $\mathrm{GaN}$ cap layer. The recess etch was done using the same RIE recipe used for $n+$ ohmic and mesa etching. A high-resistance Keithley 6517A electrometer with low-noise triax probes was used to measure the $I-V$ characteristics of the fabricated solar-blind photodiodes. All measurements were performed at room temperature. Fig. 1(a) shows the measured dark current of a $100 \times 100 \mu \mathrm{m}^{2}$ device after complete recess etch $\mathrm{GaN}$ cap layer. For reverse bias values smaller than $6 \mathrm{~V}$, the measured dark current fluctuated below the 3-fA level, which corresponds to a dark current density smaller than $3.0 \times 10^{-11} \mathrm{~A} / \mathrm{cm}^{2}$. This is the lowest dark current density measured for AlGaN-based detectors. Dark current was below $7 \mathrm{fA}$ for reverse bias values up to $10 \mathrm{~V}$. Low dark current values proved the high growth quality of AlGaN wafer with low defect density. The measured forward turn-on voltages were small $(<1 \mathrm{~V})$ and reverse breakdown behavior was observed for reverse bias values over $40 \mathrm{~V}$. Fig. 1(b) shows the dark current density measured before and after recess etch and the ultraviolet (UV) photocurrent generated by the photodiode under $4.3-\mu \mathrm{W}$ illumination at $267 \mathrm{~nm}$. The strong UV photocurrent shows that 

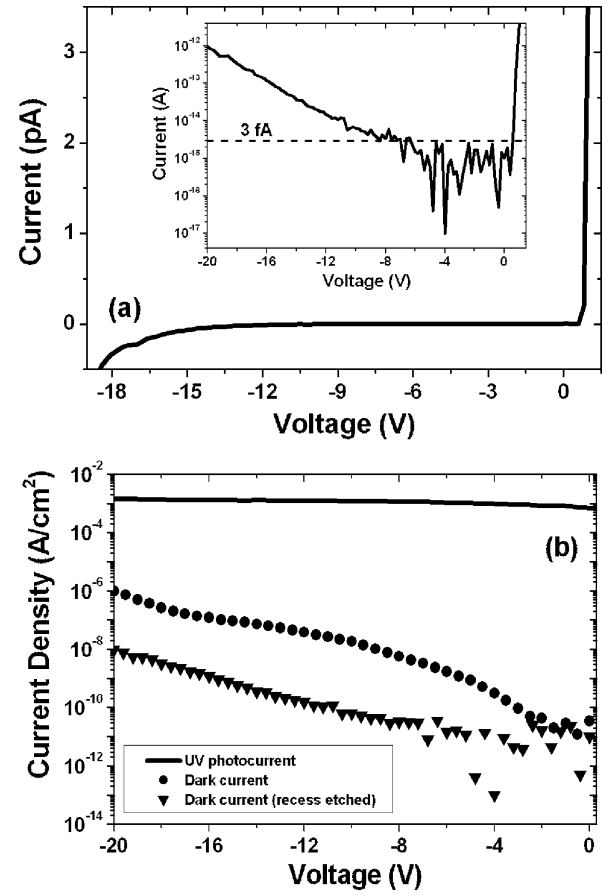

Fig. 1. (a) Dark current of a $100 \times 100 \mu \mathrm{m}^{2}$ solar-blind AlGaN photodiode. The inset shows the same plot in logarithmic scale. (b) Dark current density before/after recess etch and UV photocurrent obtained from the same device.

the detectors are operating in solar-blind spectrum. The $I-V$ measurements showed that the dark current dropped by over two orders of magnitude after the GaN cap layer was removed. This result was well expected since the lower bandgap GaN layer generates more carriers due to thermal generation. The dark current of nonrecess etched sample was below $10 \mathrm{fA}$ at a reverse bias of $3 \mathrm{~V}$.

Spectral responsivity of the solar-blind AlGaN p-i-n photodiode samples was measured using a xenon lamp light source, a single-pass monochromator, a lock-in amplifier, a chopper, a dc bias source, a multimode UV fiber, and a calibrated UV-enhanced silicon photodetector [16]. The measured spectral quantum efficiency and corresponding responsivity curves before recess etch are shown in Fig. 2(a). The device responsivity increased with applied reverse bias. Zero-bias peak responsivity of $47 \mathrm{~mA} / \mathrm{W}$ at $271 \mathrm{~nm}$ improved to $95 \mathrm{~mA} / \mathrm{W}$ for $20-\mathrm{V}$ reverse bias. Responsivity did not increase for higher reverse bias values, which indicates that the undoped $\mathrm{Al}_{0.45} \mathrm{Ga}_{0.55} \mathrm{~N}$ active layer was totally depleted at $20 \mathrm{~V}$. The corresponding peak external quantum efficiency under full depletion was $43 \%$ at 271 $\mathrm{nm}$. The cutoff wavelength of the detectors was around $283 \mathrm{~nm}$. As can be seen from the semilog plot, a visible rejection of $\sim 4$ orders of magnitude was achieved at zero bias. To observe the effect of GaN cap layer removal, this layer was recess etched in three equal $(\sim 10 \mathrm{~nm})$ steps. The corresponding responsivity curves at $10-\mathrm{V}$ reverse bias for each etch step are shown in Fig. 2(b). As the GaN cap layer was recess etched, the optical loss due to absorption within this layer was reduced, resulting in higher device responsivity. GaN cap layer was completely etched in three etch steps. The peak responsivity improved from 81 to $111 \mathrm{~mA} / \mathrm{W}$, while the peak wavelength changed from 271 to $261 \mathrm{~nm}$. The peak quantum efficiency performance achieved
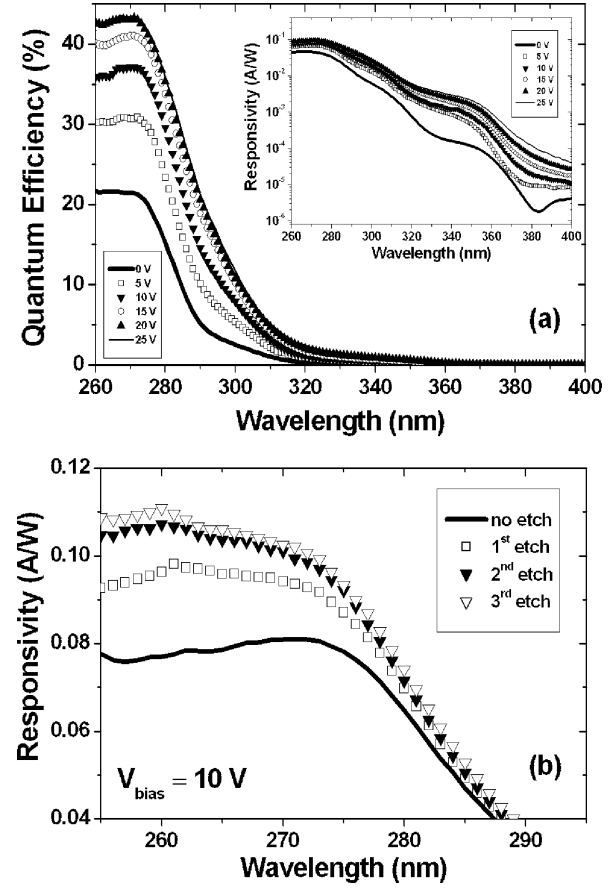

Fig. 2. (a) Spectral quantum efficiency and the corresponding responsivity curve of the nonetched solar-blind detector. (b) Spectral responsivity as a function of recess etch of the $\mathrm{p}+\mathrm{GaN}$ cap layer. The peak responsivity under $10-\mathrm{V}$ reverse bias was measured as $0.11 \mathrm{~A} / \mathrm{W}$.

after three etch steps was $53 \%$ at $261 \mathrm{~nm}$. The zero bias peak responsivity after the third etch step was measured as $65 \mathrm{~mA} / \mathrm{W}$ at $267 \mathrm{~nm}$, which will be used for detectivity calculations.

Based on the fact that the background radiation is very small with respect to the thermal noise within the solar-blind spectrum, we can safely assume that the detectivity of solar-blind detectors is thermally limited. Therefore, neglecting the background radiation component, the thermally limited specific detectivity can be calculated by $D^{*}=R_{\lambda}\left(R_{0} A / 4 k T\right)^{1 / 2}$, where $R_{\lambda}$ is the photovoltaic (zero bias) device reponsivity, $R_{0}$ is the dark impedance at zero bias which is also known as differential resistance, and $A$ is the detector area [17]. To calculate the thermally limited specific detectivity of our devices, we have determined $R_{0}$ by fitting the dark current data with a curve fitting method [18]. Fig. 3 shows the dark current measurement data of a $100 \times 100 \mu \mathrm{m}^{2}$ device and the exponential fitting curve in both logarithmic and linear scale. By taking the derivative $(d V / d I)$ of the resulting curve equation at zero bias, we obtained a differential resistance of $R_{0}=9.52 \times 10^{15} \Omega$. Combining with $R_{\lambda}=$ $65 \mathrm{~mA} / \mathrm{W}, A=10^{-4} \mathrm{~cm}^{2}$, and $T=293 \mathrm{~K}$, we achieved a detectivity performance of $D^{*}=4.9 \times 10^{14} \mathrm{~cm} \cdot \mathrm{Hz}^{1 / 2} / \mathrm{W}^{-1}$ at $267 \mathrm{~nm}$. This result shows that the room-temperature solar-blind detectivity performance of these AlGaN p-i-n photodiodes exceed the typical detectivity performance of a cooled PMT detector.

In summary, we have reported high-performance solar-blind AlGaN p-i-n photodiodes with low dark current and high solar-blind detectivity performance. Improvement in dark current and responsivity performance was observed with the removal of GaN cap layer. The recess etched p-i-n detectors exhibited extremely low dark current density 


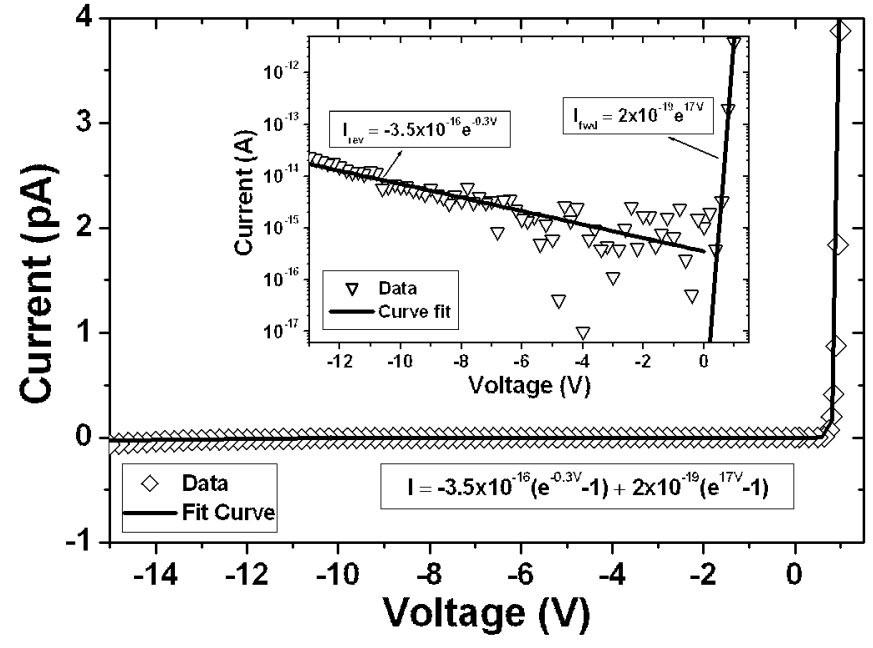

Fig. 3. Exponential curve fitting to the measured dark current of a $100 \times 100 \mu \mathrm{m}^{2}$ device. Inset figure shows the reverse and forward bias part fitting curves separately in a semilog plot. From the fitting curve equation, differential resistance (dark impedance) of the solar-blind detector was calculated as $R_{0}=9.52 \times 10^{15} \Omega$

$\left(<3 \times 10^{-11} \mathrm{~A} / \mathrm{cm}^{2}\right.$ at $\left.6 \mathrm{~V}\right)$ and a peak quantum efficiency of $53 \%$ at $261 \mathrm{~nm}$ under $10-\mathrm{V}$ reverse bias. Low dark current values resulted in a very high differential resistance of $R_{0}=9.52 \times 10^{15} \Omega$. The solar-blind detectivity was calculated as $D^{*}=4.9 \times 10^{14} \mathrm{~cm} \cdot \mathrm{Hz}^{1 / 2} / \mathrm{W}^{-1}$ at $267 \mathrm{~nm}$, which corresponds to the highest detectivity performance reported for AlGaN-based solar-blind detectors.

\section{REFERENCES}

[1] M. Razeghi and A. Rogalski, "Semiconductor ultraviolet detectors," $J$. Appl. Phys., vol. 79, pp. 7433-7473, 1996.

[2] J. C. Carrano, T. Li, P. A. Grudowski, R. D. Dupuis, and J. C. Campbell, "Improved detection of the invisible," IEEE Circuits Devices Mag., vol. 15, pp. 15-24, Sept. 1999.

[3] A. Osinsky, S. Gangopadhyay, B. W. Lim, M. Z. Anwar, M. A. Khan, D. V. Kuksenkov, and H. Temkin, "Schottky barrier photodetectors based on AlGaN," Appl. Phys. Lett., vol. 72, pp. 742-744, 1998.
[4] D. Walker, X. Zhang, P. Kung, A. Saxler, S. Javapor, J. Xu, and M. Razeghi, "AlGaN ultraviolet photoconductors grown on sapphire," Appl. Phys. Lett., vol. 68, pp. 2100-2101, 1996.

[5] E. Monroy, F. Calle, J. L. Pau, F. J. Sanchez, E. Munoz, F. Omnes, B. Beaumont, and P. Gibart, "Analysis and modeling of $\mathrm{Al}_{x} \mathrm{Ga}_{1-x} \mathrm{~N}$-based Schottky barrier photodiodes," J. Appl. Phys., vol. 88, pp. 2081-2091, 2000 .

[6] V. Adivarahan, G. Simin, G. Tamulaitis, R. Srinivasan, J. Yang, M. A. Khan, M. S. Shur, and R. Gaska, "Indium-silicon codoping of high-aluminum-content AlGaN for solar blind photodetectors," Appl. Phys. Lett., vol. 79, pp. 1903-1905, 2001.

[7] M. M. Wong, U. Chowdhury, C. J. Collins, B. Yang, J. C. Denyszyn, K. S. Kim, J. C. Campbell, and R. D. Dupuis, "High quantum efficiency AlGaN/GaN solar-blind photodetectors grown by metalorganic chemical vapor deposition," Phys. Stat. Sol. A, vol. 188, pp. 333-336, 2001.

[8] V. V. Kuryatkov, H. Temkin, J. C. Campbell, and R. D. Dupuis, "Lownoise photodetectors based on heterojunctions of AlGaN-GaN," Appl. Phys. Lett., vol. 78, pp. 3340-3342, 2001.

[9] N. Biyikli, O. Aytur, I. Kimukin, T. Tut, and E. Ozbay, "Solar-blind AlGaN-based Schottky photodiodes with low noise and high detectivity," Appl. Phys. Lett., vol. 81, pp. 3272-3274, 2002.

[10] J. Y. Duboz, J. L. Reverchon, D. Adam, B. Damilano, F. Semond, N. Grandjean, and J. Massies, "High performance solar blind detectors based on AlGaN grown by MBE on Si," Phys. Stat. Sol. A, vol. 188, pp. 325-328, 2001.

[11] N. Biyikli, I. Kimukin, T. Kartaloglu, O. Aytur, and E. Ozbay, "Highspeed solar-blind photodetectors with indium-tin-oxide Schottky contacts," Appl. Phys. Lett., vol. 82, pp. 2344-2346, 2003.

[12] A. Hirano, C. Pernot, M. Iwaya, T. Detchprohm, H. Amano, and I. Akasaki, "Demonstration of flame detection in room light background by solar-blind AlGaN pin photodiode," Phys. Stat. Sol. A, vol. 188, pp. 293-296, 2001.

[13] J. D. Brown, Z. Yu, J. Matthews, S. Harney, J. Boney, J. F. Schetzina, J. D. Benson, K. W. Dang, C. Terrill, T. Nohava, W. Yang, and S. Krishnankutty. (1999) Visible-blind UV digital camera based on a $32 \times 32$ array of GaN/AlGaN p-i-n photodiodes. MRS Internet J. Nitride Semicond. Res. [Online]Article 9

[14] C. J. Collins, U. Chowdhury, M. M. Wong, B. Yang, A. L. Beck, R. D. Dupuis, and J. C. Campbell, "Improved solar-blind external quantum efficiency of back-illuminated $\mathrm{Al}_{x} \mathrm{Ga}_{1-x} \mathrm{~N}$ heterojunction $\mathrm{p}$-i-n photodiodes," Electron. Lett., vol. 38, pp. 824-826, 2002.

[15] N. Biyikli, T. Kartaloglu, O. Aytur, I. Kimukin, and E. Ozbay, "High-speed visible-blind GaN-based indium-tin-oxide Schottky photodiodes," Appl. Phys. Lett., vol. 79, pp. 2838-2840, 2001.

[16] — , (2003) High-performance solar-blind AlGaN Schottky photodiodes. MRS Internet J. Nitride Semicond. Res. [Online]Article 2

[17] S. Donati, Photodetectors: Devices, Circuits, and Applications. Englewood Cliffs, NJ: Prentice-Hall, 2000.

[18] C. J. Collins, T. Li, D. J. H. Lambert, M. M. Wong, R. D. Dupuis, and J. C. Campbell, "Selective regrowth of $\mathrm{Al}_{0.30} \mathrm{Ga}_{0.70} \mathrm{~N}$ p-i-n photodiodes," Appl. Phys. Lett., vol. 77, pp. 2810-2812, 2000. 